\title{
Influence of Shot Peening Parameters on Residual Stresses in Flake and Vermicular Cast Irons
}

\author{
Mattias Lundberg ${ }^{1, a}$, Ru Lin Peng ${ }^{1, b}$, Maqsood Ahmad ${ }^{2, c}$, Taina Vuoristo ${ }^{3, d}$, \\ Daniel Bäckström ${ }^{3, e}$, Sten Johansson ${ }^{1, f}$ \\ ${ }^{1}$ Department of Management and Engineering, Linköping University, SE-58183 Linköping, Sweden \\ ${ }^{2}$ Base Engine \& Materials Technology, Volvo Powertrain, SE-40508 Gothenburg, Sweden \\ ${ }^{3}$ Testing Methods and Testing, Scania CV AB, SE-15187 Södertälje, Sweden \\ amattias.lundberg@liu.se, ${ }^{\mathrm{b}}$ ru.peng@liu.se, ${ }^{\mathrm{C}}$ maqsood.ahmad@volvo.com, \\ dDaniel.Backstrom@scania.com, ${ }^{\mathrm{d}}$ taina.vuoristo@scania.com, ${ }^{\mathrm{f}}$ sten.johansson@liu.se
}

Keywords: residual stress, cast iron, shot peening, x-ray diffraction

\begin{abstract}
Test samples of grey and compacted graphite cast irons with pearlitic matrix were shotpeened to different surface conditions using twelve different combinations of shot size, peening intensity and peening coverage percentage. Relatively high surface compressive residual stresses varying between 245 to $565 \mathrm{MPa}$ were observed and the compressive residual stresses reached a depth between $280 \mu \mathrm{m}$ and $770 \mu \mathrm{m}$. Within the range of peening parameters used, the compacted graphite cast iron with its vermicular graphite showed a somewhat better response to the same shotpeening treatment than the grey cast iron containing flake graphite, giving a larger peening affected zone with higher compressive residual stresses. For both the cast irons, an increase in peening coverage percentage, shot size or peening intensity led often to a lower surface compressive stress. However, peening using a higher intensity greatly increased the degree and extent of plastic deformation and therefore increased the magnitude and penetration depth of the subsurface compressive residual stresses, while the effect of increasing shot size also depends on the peening intensity. On the other hand, measurements on the grey cast iron samples showed that the peening coverage has little effect on the depth profile of residual stress.
\end{abstract}

\section{Introduction}

Shot peening is an effective way to increase the fatigue strength of steel components in the high cycle fatigue (HCF) regime. The beneficial effect is attributed to compressive residual stresses and strain hardening induced by the shot peening in the surface layer of the components. The effect of such a surface mechanical treatment on cast irons is much less studied and the limited work found in the literature focuses mainly on ductile and austempered ductile cast irons [1-6]. Shot blast cleaning, an operation similar to shot peening, is widely used to remove mould sands, oxide scale and other particles retained in the cast iron surfaces after casting. Compressive residual stresses are induced in the surface and subsurface in ductile and grey cast irons [7]. The process is, however, not as well controlled as shot peening which is dedicated to surface modification to increase fatigue resistance of products. The results from shot peening ductile and austempered ductile cast irons vary but the fatigue strength has been reported to increase between 20-150\% [2-5]. Surface compressive stress of almost twice the $0.2 \%$ proof stress of an austenitic ductile iron has been reported in [3]. Investigations have showed that the peening intensity, shot size and strength of the ductile iron were important for the magnitude and penetration depth of the compressive residual stress [5]. How flake and vermicular cast irons respond to shot peening has not been thoroughly investigated, which has therefore become the aim of the current work. The ultimate goal of the project is to improve the fatigue strength of the two cast irons through optimising residual stresses.

It is well recognised that shot peening results depend on both the target material and a number of peening parameters. Industrial process is often controlled through choices of peening media, i.e. type of shots and size, Almen intensity and degree of peening coverage. Based on the limited 
publications on shot peening of cast irons found in the literature, twelve unique combinations of shot size, intensity and coverage were used to shot peen a flake and a vermicular cast iron of pearlitic matrix. This paper presents investigations of the influence of the selected shot peening parameters on deformation depth and residual stress distribution. In a parallel paper published in the current volumes [8], the influence of graphite morphology on the shot peening results is analysed.

\section{Experimental Details}

Material. Both materials have essentially a pearlitic matrix and the chemical composition is given in Table 1. As shown in Fig. 1, the flake cast iron (GI) consists of a pretty homogeny flaky graphite structure while the vermicular cast iron (CGI) contains both vermicular graphite and a small amount of nodular graphite. The two irons were annealed to reduce possible thermal residual stresses from the casting process. Nominal mechanical properties and micro hardness measured in the matrix are listed in Table 2.

Table 1 Nominal chemical composition

\begin{tabular}{|l|c|c|c|c|c|c|c|c|l|}
\hline & $\mathrm{C}$ & $\mathrm{Si}$ & $\mathrm{Mn}$ & $\mathrm{P}$ & $\mathrm{S}$ & $\mathrm{Cu}$ & $\mathrm{Cr}$ & $\mathrm{Mo}$ & \multicolumn{1}{|c|}{$\mathrm{Fe}$} \\
\hline Grey iron & 3.1 & 1.8 & 0.65 & $\begin{array}{l}\mathrm{Max} \\
0.08\end{array}$ & 0.12 & 0.90 & 0.14 & 0.25 & Bal. \\
\hline Compacted graphite iron & 3.8 & 2.0 & 0.20 & $\begin{array}{l}\text { Max } \\
0.05\end{array}$ & 0.01 & 0.90 & 0.02 & 0.005 & Bal. \\
\hline
\end{tabular}

Table 2 Nominal mechanical properties (tensile test)

\begin{tabular}{|c|c|c|c|c|c|}
\hline Material & $\begin{array}{c}\text { Young's } \\
\text { modulus (GPa) }\end{array}$ & $\begin{array}{c}\text { Rp0,2 } \\
(\mathrm{MPa})\end{array}$ & $\begin{array}{c}\text { Rm } \\
(\mathrm{MPa})\end{array}$ & $\begin{array}{c}\text { Elongation } \\
(\%)\end{array}$ & $\begin{array}{c}\text { Matrix hardness } \\
(\mathrm{HV})\end{array}$ \\
\hline GI & $105-125$ & 260 & 290 & $0.6-0.7$ & $298 \pm 20$ \\
\hline CGI & $140-150$ & 280 & 400 & $>=1-3.5$ & $296 \pm 45$ \\
\hline
\end{tabular}
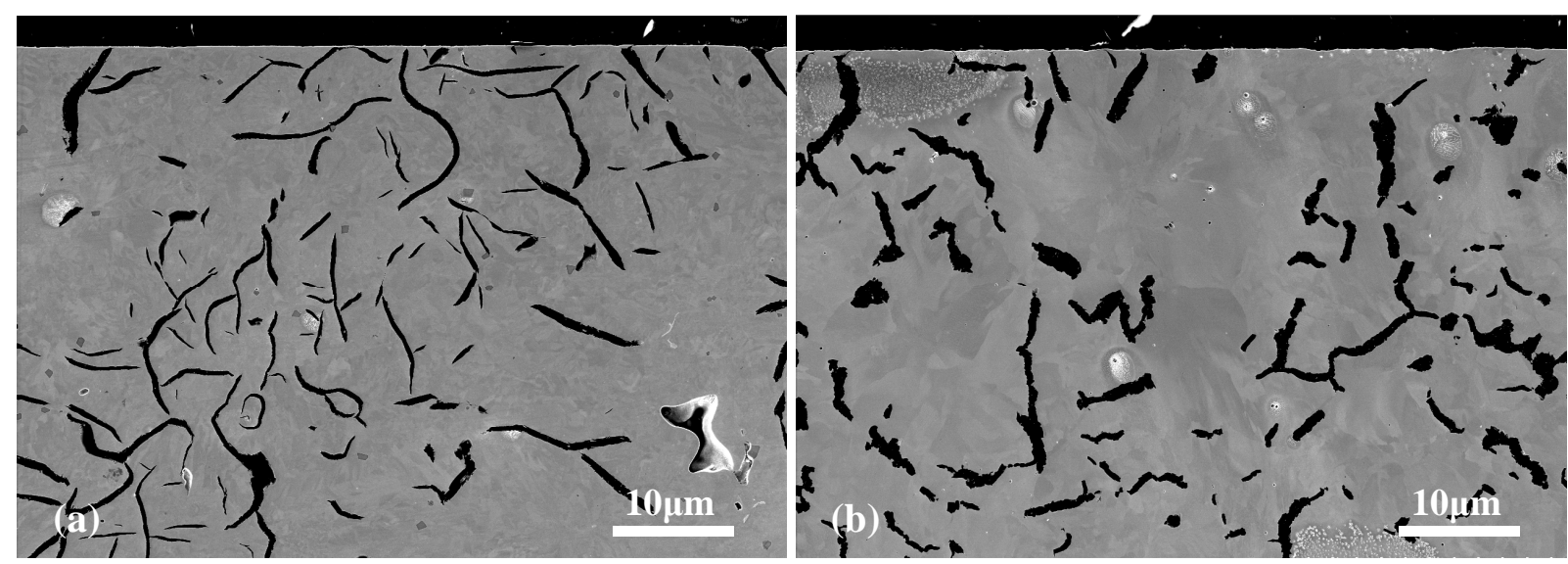

Fig. 1 Microstructure of (a) GI showing flaky graphite and (b) CGI with vermicular graphite and a small amount of nodular graphite.

Shot peening. Cylindrical samples of $\Phi 30 \mathrm{~mm} \times 9 \mathrm{~mm}$ were machined from the annealed castings of GI and CGI and the end surface was mechanically polished before shot peening. From literature survey on shot peening of ductile cast irons, steels shots of three different sizes, S170, S330 and S550, with a hardness of HRC 56 were selected combined with two peening coverage percentages and two levels of peening intensity. As given in Table 3, twelve unique combinations of shot peening parameters were studied for each material. Coverage here is defined as the percentage of a surface area that has been indented at least once. In practice when $98 \%$ of the peened surface area is observed under optical microscope to be covered by indents a $100 \%$ coverage is considered to be achieved. The $300 \%$ coverage here was obtained by extending the shot peening duration to 3 times 
of the minimal time required to obtain $100 \%$ coverage. The peening intensity, related to the mass and velocity of the shots striking the surface, is determined by measuring the arc height of Almen strip peened to saturation according to the procedure described in [17]. Because of the larger mass difference between the chosen shot sizes, Almen A was used for S330 with low intensity and S170 but Almen C for S330 with high intensity and S550.

Microcracks associated with graphite or other types of inclusions were observed in the shot peened samples which penetrate deeper into the material with increasing peening intensity.

Table 3 Shot peening parameters

\begin{tabular}{|l|l|l|l|l|}
\hline \multicolumn{2}{|l|}{ Shot size, $\Phi(\mathrm{mm})$} & $0.43(\mathrm{~S} 170)$ & $0.84(\mathrm{~S} 330)$ & $1.40(\mathrm{~S} 550)$ \\
\hline $\begin{array}{l}\text { Intensity } \\
\text { Almen }\end{array}$ & Low & $0.17 \mathrm{mmA}$ & $0.30 \mathrm{mmA}$ & $0.17 \mathrm{mmC}$ \\
\cline { 2 - 5 } Coverage $(\%)$ & High & $0.37 \mathrm{mmA}$ & $0.16 \mathrm{mmC}$ & $0.29 \mathrm{mmC}$ \\
\hline
\end{tabular}

X-ray Diffraction Measurements. The magnitude and distribution of residual stresses were investigated by x-ray diffraction. The measurements were carried out on a four-circle Seifert x-ray diffractometer equipped with a linear position sensitive detector. A $\Phi 2 \mathrm{~mm}$ collimator was used to limit the size of the irradiated area which was always centered in the surface. With $\mathrm{Cr}-\mathrm{K} \alpha$ radiation, diffraction peaks from the 211-planes of ferrite $(\alpha-\mathrm{Fe})$ were obtained. Nine $\psi$-angles spreading in equal $\sin ^{2} \psi$ intervals between $\psi=-55^{\circ}$ and $\psi=55^{\circ}$ were measured in $\psi$-mode with the tilting axis lying in the diffractometer plane. The obtained diffraction peaks were fitted with two pseudo-Voigt functions for $\mathrm{K}_{\alpha 1}$ and $\mathrm{K}_{\alpha 2}$ to determine diffraction peak positions and widths. Residual stresses were then calculated according to the standard $\sin ^{2} \psi$ method [9] with an x-ray elastic constant of $5.8 \times 10^{-6}$ $\mathrm{MPa}^{-1}$ which is often used for the ferrite 211-planes in steels. It should be pointed out that the measured residual stress includes also phase stress locally balanced with the cementite phase. Such stresses originate from different thermal and mechanical properties of the ferrite and cementite in the matrix [10].

\section{Results and Discussion}

Surface residual stresses. Fig. 2 compares surface residual stresses for the GI samples peened with different parameters according to Table 3. In general, increasing peening intensity, coverage or shot size results in lower surface compressive residual stress. Consequently, the largest compressive surface stress $(500 \mathrm{MPa})$ was obtained for peening with the smallest shot (S170), 100\% coverage, and low intensity $(0.17 \mathrm{mmA})$. Increasing the shot size or increasing the peening intensity leads to a lower surface stress. Shot peening using the largest shot (S550), 300\% coverage and high peening intensity $(0.29 \mathrm{mmC})$ has the lowest compressive surface stress, about $200 \mathrm{MPa}$.

The same trend is also observed for the CGI, as revealed in Fig. 3. With identical peening variables, CGI shows somewhat higher compressive surface stresses than GI. The maximum compressive stress reaches about $560 \mathrm{MPa}$ and the minimum is $290 \mathrm{MPa}$.

Residual stress depth profiles in flake cast iron. Derived from the mechanism for fatigue crack initiation and propagation, the magnitude and variation of subsurface compressive residual stress are important for the fatigue performance. For example, improvement in fatigue life was found to be correlated to the area under the residual stress distribution curve in a shot peened spring steel [11]. Therefore, residual stress distribution versus depth below the peened surface was also measured on selected samples. The results are presented in Figs. 4-8, together with the

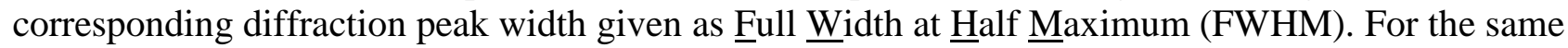
instrumental setup, changes in diffraction peak width can then be associated with changes in grain/domain size and microstrains in the probed volume. Except for a thin surface layer where ferrite grain refinement was observed, the detected peak broadening in those shot peened samples studied here can be attributed mainly to plastic deformation. Therefore, the FWHM distribution 
with depth is also used below as an indication for both the degree of local plastic deformation and the penetration depth of the plastic deformation from the shot peening process.

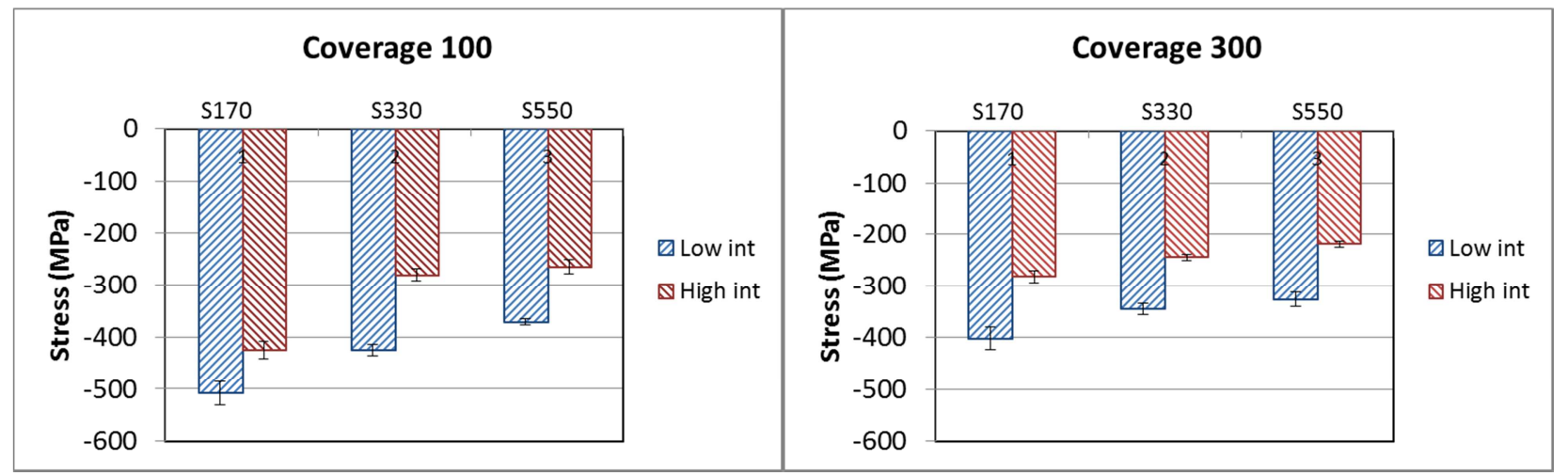

Fig. 2 Surface residual stresses in GI peened using different combination of shot size, peening intensity and peening coverage, see Table 3 .

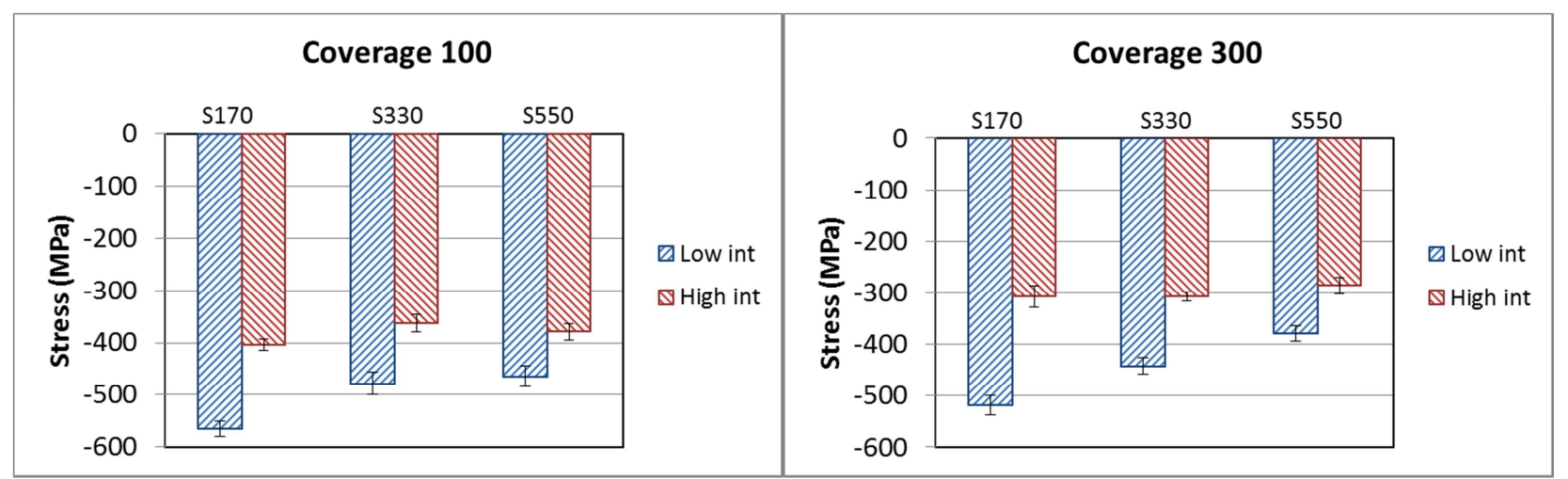

Fig. 3 Residual stresses in CGI iron peened using different combination of shot size, peening intensity and peening coverage, see Table 3 .

Results from peening of the GI using S170 are plotted in Fig.4. As can be seen, compressive residual stresses are induced in a significant surface layer in all the three samples. The plastically affected depth, revealed by the FWHM profile, is somewhat smaller than the compressive zone. The small difference between the two could be associated with slight stress relaxation by electrolytic polishing or the phase stresses balanced between the ferrite and cementite. For the low intensity of $0.17 \mathrm{mmA}$ and $100 \%$ coverage, the compressive stress drops rapidly from $500 \mathrm{MPa}$ to about 120 $\mathrm{MPa}$ within the first $60 \mu \mathrm{m}$. It then slowly decreases to approach zero at about $300 \mu \mathrm{m}$ below the peened surface. Increasing the peening coverage from $100 \%$ to $300 \%$ reduces the surface residual stress, as already mentioned above, but slightly raises the compressive stress in subsurface. While whether a full surface coverage is optimal from the point of view of fatigue resistance is disputed [12], the coverage effect on residual stresses can be related to the cyclic behaviour of the peened material [13]. Peening coverage is a parameter related to the number of shots that impinge upon the surface during the duration of shot peening. The shots arrive at different times and the impact force from shots striking the same point or slightly different location leads to cyclically loading and unloading. Apparently, at 100\% coverage the peening affected depth of the GI approaches the saturated stage of cyclic loading. Further bombardment of the surface has therefore a small effect on the subsurface plastic deformation, which is confirmed by the small change in the FWHM profile. The lower surface compressive stress could probably be attributed to a slight relaxation induced by the impact of shots. 


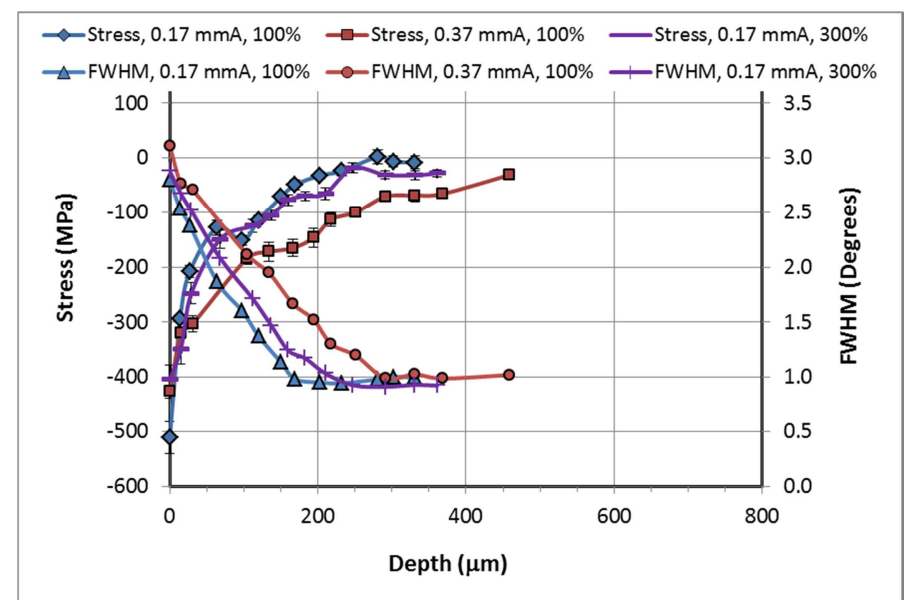

Fig. 4 Residual stresses and diffraction peak width for the GI shot peened with small shot S170.

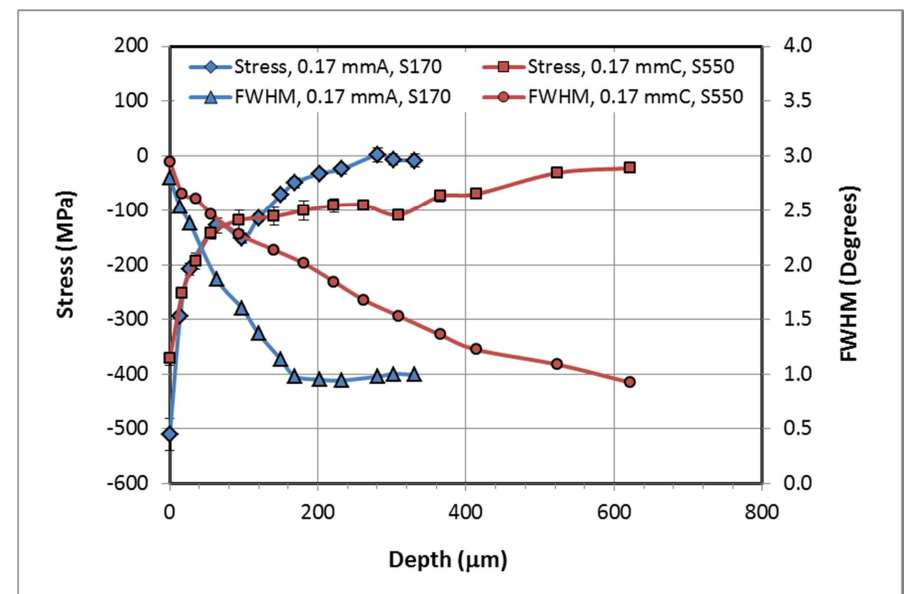

Fig. 5 Residual stresses and diffraction peak width for the GI shot peened with different shot size but same $100 \%$ coverage.

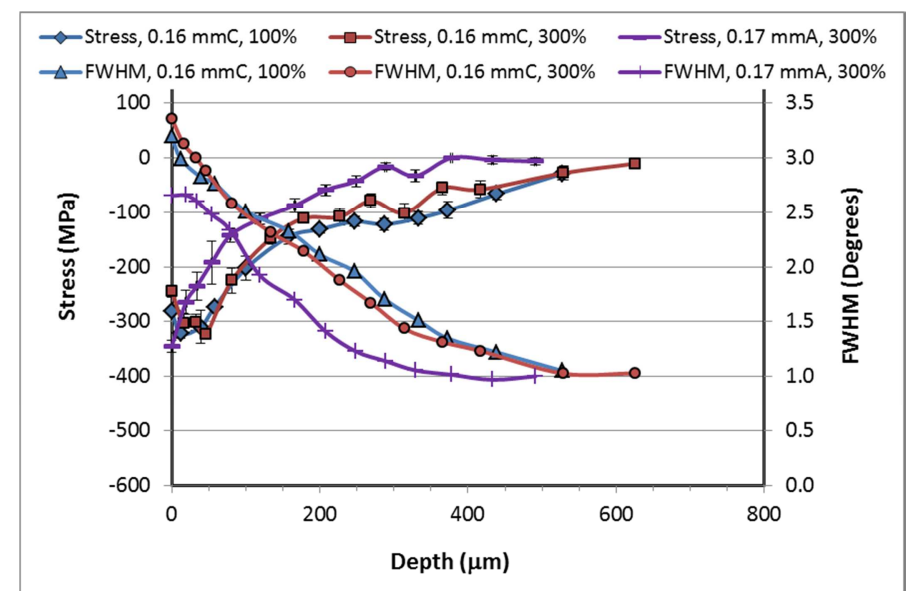

Fig. 6 Residual stresses and diffraction peak width for GI shot peened using S330 shots.

In contrast to the influence of coverage, increasing the peening intensity has a greater influence (Fig. 4). At the peening intensity of $0.37 \mathrm{mmA}$, the subsurface compressive residual stress after an initial rapid drop decreases more slowly and reaches zero stress at a depth beyond $500 \mu \mathrm{m}$. With the same shot mass, increasing intensity means a higher impact speed. Because of the increased kinetic energy, the degree of plastic deformation and its penetration in the sample is significantly increased, see the FWHM profiles in Figs. 4-6. A much larger compression zone with higher subsurface compressive stresses is therefore induced. The result differs, however, from previous investigations 
on ductile cast irons [5], which showed that increasing peening intensity had no obvious influence on the thickness of the compression zone but increased the subsurface compressive surface in the ductile irons with higher yield strength.

Significant influence of shot size is revealed by Fig. 5 in which results from the low intensity and $100 \%$ coverage peening are plotted. For S550, the compressive stress drops rapidly, following the same trend as peening with S170, and arrives at a stress "plateau" at about $100 \mu \mathrm{m}$. The sluggish behaviour of the residual stress is observed between 100 and $330 \mu \mathrm{m}$. At larger depths, the residual stress decreases slowly to approach zero stress beyond $600 \mu \mathrm{m}$. The FWHM distribution reveals that the plastic zone is three times of S170, which can be attributed to the much higher kinetic energy related to the large mass of the shots and the higher Almen intensity.

For shot peening using the "medium" size shots (S330) Fig. 6 show that the high intensity 0.16 mmC induces a compression zone of about $600 \mu \mathrm{m}$ which is similar to that of peening by S550 at slightly higher intensity of $0.17 \mathrm{mmC}$. Again, the different peening coverage makes essentially no difference in terms of residual stress distribution and plastic deformation depth. Except for the low intensity and $100 \%$ coverage shot peening, the maximum compressive stress appears in subsurface and is independent of the Almen intensity and shot diameter. It is worth pointing out that increasing shot size expands mainly the low compressive residual stress depth at low peening intensity (Fig. 5) but at high intensity increases significantly the subsurface compressive stress magnitude and its penetration depth (Fig. 6).

With a maximum compressive stress at the surface and a large zone of low compressive stress in subsurface, the obtained residual stress distributions for peening of GI with low intensity (Fig. 4-6) deviates from the classical distribution found for shot peening which often display subsurface compressive stress peak $[11,13,14]$. Other shapes of residual stress curves, e.g. with a surface stress plateau, were also found in the literature but less common. Some of the non-classical stress distributions could be related to multi-peening [14,15] or peening induced phase transformation [4]. Measurements on steels of different yield strengths [16] showed that the strength of the target material can also be important. For ten different strength grades of steels, subsurface compressive maximum was found for all, except in one steel with low yield strength of $340 \mathrm{MPa}$. Sigmoid shaped stress profiles similar to the cast irons peened at low intensity were observed. The limited residual stress curves found on cast irons often possess a subsurface compressive peak [5]. Investigations on ductile cast iron [1] showed a surface maximum in the iron with a pearlitic matrix but a subsurface maximum peak for the iron with a matrix of pearlite and ferrite and a subsurface plateau was also observed in both irons. Given the microstructure of cast irons which contains a considerable amount of graphite, the more complex stress distributions with maximum surface compressive stress and subsurface compressive stress plateau could probably be explained by the interferes of graphite with the propagation of plastic deformation into depth, as observed in [8]. Graphite in the peening affected depth can damp plastic deformation but can also result in plastic strain concentration. Further work is needed to confirm this suggestion.

Residual stress depth profiles in vermicular cast iron. The preceding analyses on GI reveal a large influence of both the peening intensity and shot size but a minor effect of the peening coverage percentage. Therefore residual stress depth profiling on CGI was concentrated on comparing the intensity and shot size for $100 \%$ coverage. Figs. 7 and 8 show that changing the peening intensity and shot size also significantly changes the residual stress distribution in the CGI. For peening using S170 shots, the high peening intensity $(0.37 \mathrm{mmA})$ greatly expands the subsurface compression zone. However, different from GI, a small subsurface maximal appears. Furthermore, the subsurface compressive stress plateau becomes wider and the plateau compressive stress, at about $260 \mathrm{MPa}$, is higher than GI. Actually, a careful comparison of Fig. 7 with Fig. 4 also discloses higher subsurface compressive residual stresses and larger compression zone in CGI. The better response of CGI to shot peening can be related to its microstructure and properties. The analyses in [8] show that the flaky graphite in the GI more effectively reduces propagation of plastic deformation from the impact surface and the CGI matrix has better capability for plastic deformation. 
Peening with S330 shots mostly affect the subsurface residual stresses. The stress distributions given in Fig. 7(b) resemble those in Fig. 7(a), however, with a much wider surface stress plateau. It is also interesting to note that peening with S330 shots at $0.30 \mathrm{mmA}$ produces almost the same results as peening using S170 shots at $0.37 \mathrm{mmA}$. Except for a very thin surface layer, which could be related to a somewhat higher degree of plastic deformation, essentially same residual stress distributions were observed.

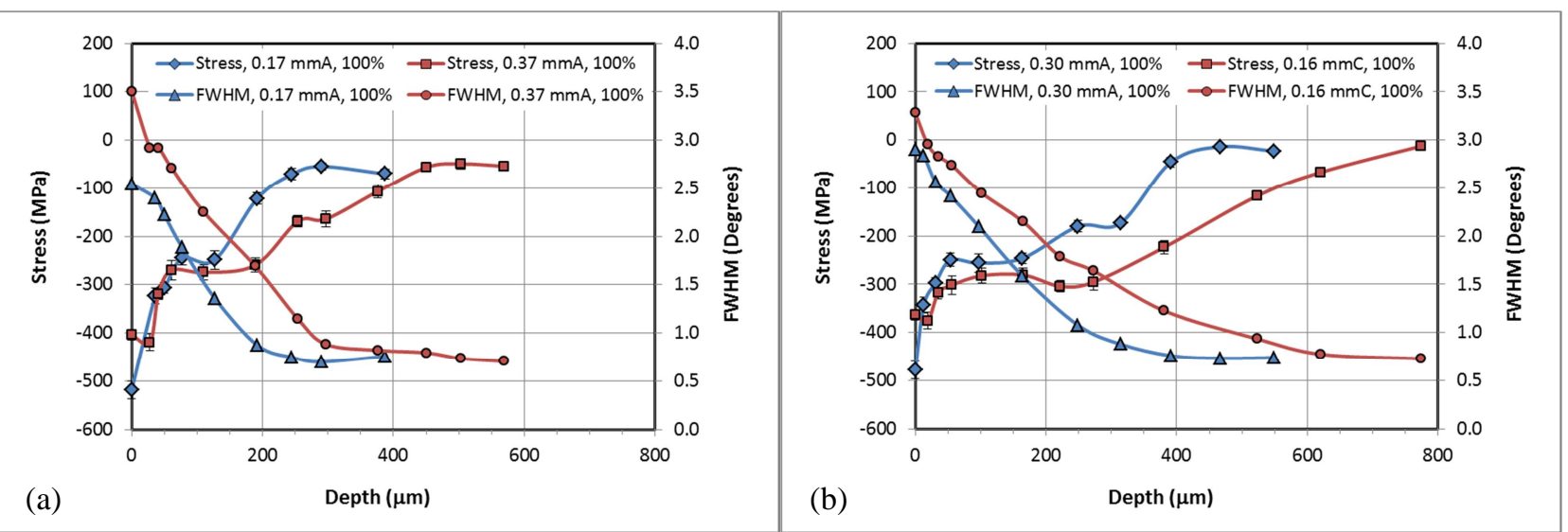

Fig. 7 Residual stresses and diffraction peak width for CGI shot peened using S170 shots and 100\% coverage (a) and S330 shots and $100 \%$ coverage (b).

\section{Conclusions}

Twelve shot peening treatments combining different shot sizes, peening coverage percentage and peening intensities were applied to a flake cast iron and a vermicular cast iron. The induced surface residual stresses and subsurface residual stress distributions as well as the plastically deformed depth were investigated by x-ray diffraction. The main observations are summarized below.

Relatively high compressive residual stresses have been induced in the surface of all the samples. For both GI and CGI, the largest surface residual stress was found for peening with the smallest shots (S170), low intensity $(0.17 \mathrm{mmA})$ and $100 \%$ peening coverage and the lowest surface stress for peening with the largest shots (S550), high intensity $(0.29 \mathrm{mmC})$ and $300 \%$ peening coverage.

Increased coverage from $100 \%$ to $300 \%$ has a minor effect on the subsurface residual stress distribution as measurements on selected GI samples show. This is explained by a small effect of further peening on the cyclic behavior of the cast iron.

Peening with a high intensity has a large effect on the residual stress depth profiles. The subsurface layer with compressive residual stresses was greatly increased for both the GI and CGI due to a larger depth of plastic deformation.

At low peening intensity, increasing shot size affects more significantly the penetration depth of the low compressive stress zone than the compressive stresses in the immediate subsurface layer.

\section{Acknowledgement}

Financial supports from VINNOVA - Sweden's Innovation Agency through the program FFI Strategic Vehicle Research and Innovation, Scania CV AB and Volvo Powertrain AB are greatly appreciated. The authors are also thankful to Mrs A. Billenius for helps with sample preparations and certain experiments.

\section{References}

[1] Y. Ochi, K. Masaki, T. Matsumura, T. Sekino, Effect of shot-peening treatment on high cycle fatigue property of ductile cast iron, Int. J. Fatigue. 23 (2001) 441-8. 
[2] S. Ji, K. Roberts, Z. Fan, Effect of shot peening on fatigue performance of ductile iron castings, Materials Science and Technology. 18 (2002) 193-7.

[3] D. Kirk, D.G. Birch, Residual stresses induced by peening austenitic ductile cast-iron, ICSP7: 7th International Conference on Shot Peening; Warsaw; Poland; 29 Sept.-1 Oct. 1999. (1999).

[4] A. Zammit, M. Mhaede, M. Grech, S. Abela, L. Wagner, Influence of shot peening on the fatigue life of $\mathrm{Cu}-\mathrm{Ni}$ austempered ductile iron, Materials Science and Engineering: A. 545 (2012) 78-85.

[5] S.P. Simonin, J.F. Flavenot, Shot Peening of Nodular Cast Iron. (Retroactive Coverage), Shot Peening: Science, Technology; Application, Garmisch-Partenkirchen; FRG; 1987. (1987) 133-140.

[6] M. Lawerenz, Shot Peening Ductile Iron, Mod. Cast. 80 (1990) 51-53.

[7] S.S. Mroz, G.M. Goodrich, Quantification of Shot Blast Cleaning Effects on Cast Iron as Cast Surfaces, Transactions of the American Foundry Society, Vol. 114. 114 (2006) 493-506.

[8] M. Lundberg, R. Lin Peng, M. Ahmad, D. Backström, T. Vouristo, S. Johansson, Graphite Morphology’s Influence on Shot Peening Results in Cast Irons, Current volumes (2013).

[9] I.C. Noyan, J.B. Cohen, Residual Stress Measurement by Diffraction and Interpretation, (1987).

[10] M. Martinez-Perez, F.J. Mompean, J. Ruiz-Hervias, C.R. Borlado, J.M. Atienza, M. GarciaHernandez, M. Elices, J. Gil-Sevillano, L.P. Ru, T. Buslaps, Residual stress profiling in the ferrite and cementite phases of cold-drawn steel rods by synchrotron X-ray and neutron diffraction, Acta Materialia. 52 (2004) 5303-13.

[11] G.H. Farrahi, J.L. Lebrun, D. Couratin, Effect of shot peening on residual stress and fatigue life of a spring steel, Fatigue and Fracture of Engineering Materials and Structures (United Kingdom). 18 (1995) 211-220.

[12] S. Bagherifard, R. Ghelichi, M. Guagliano, On the shot peening surface coverage and its assessment by means of finite element simulation: A critical review and some original developments, Appl. Surf. Sci. 259 (2012) 186-94.

[13] R. Fathallah, W. Cao, L. Castex, P.S. Webster, Effects of shot peening parameters on introduced residual stresses, Proceedings of the Fourth International Conference on Residual Stresses; Baltimore, Maryland; USA; 8-10 June 1994. (1994).

[14] G. Olmi, M. Comandini, A. Freddi, Fatigue on Shot-Peened Gears: Experimentation, Simulation and Sensitivity Analyses, Strain.Newcastle-upon-Tyne. 46 (2010) 382-395.

[15] K. Zhan, C. Jiang, X. Wu, V. Ji, Surface Layer Characteristics of S30432 Austenite Stainless Steel after Shot Peening, Materials Transactions. (2012) 1002-1006.

[16] S. Wang, Y. Li, M. Yao, R. Wang, Compressive residual stress introduced by shot peening, J. Mater. Process. Technol. 73 (1998) 64-73.

[17] M. Lawerenz, Shot Peening Ductile Iron, Modern Casting. (1990) 51-53. 